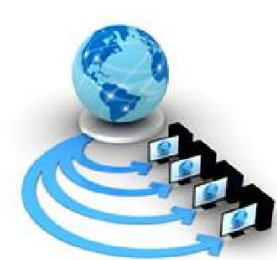

Volume 11, No. 3, May-June 2020

\title{
IOT BASED AUTOMATIC RAIN WATER HARVESTING AND IRRIGATION SYSTEM
}

\author{
D.SRINATH REDDY \\ Computer science and information technology, \\ REVA UNIVERSITY, \\ Bengaluru, India \\ CH.SAI TEJA \\ Computer science and information technology, \\ REVA UNIVERSITY, \\ Bengaluru, India
}

\author{
B.SAI NISHANTH \\ Computer science and information technology, \\ REVA UNIVERSITY, \\ Bengaluru, India \\ D.VARUN REDDY \\ Computer science and information technology, \\ REVA UNIVERSITY, \\ Bengaluru, India
}

Prof. AKRAM PASHA

Computer science and information technology, REVA UNIVERSITY, Bengaluru, India

\begin{abstract}
All living species in the world need is water. These days, water consumption in family units has expanded because of the illadvised utilization of water in different exercises, for example, cultivating, vehicle washing or family unit cleaning. This causes water shortage and an expansion in family unit financial consumption.Today, farmers have a few issues in agriculture because of absence of downpours and shortage of water. The primary adage of this task is to spare time and exertion of each farmer by utilizing the water collecting strategy in a manual or programmed method of utilization. Manual intercession is required for conventional farmland procedures. Human intervention can be constrained with the motorized development of water framework. By utilizing soil dampness sensor levels of soil dampness/mugginess can be checked. At whatever point there is an adjustment in stickiness in the dirt this sensor detects the change and an intrude on signal is passed to the microcontroller and relying upon this the water system framework works. The mechanized water system framework gives a web interface to the client with the goal that the client can screen and control the framework remotely i.e., can make the water system framework ON and OFF remotely. The rainwater harvesting system can reduce the water shortage and useful in various situations.In view of measurable data accessible during quite a while, a reproduction framework is worked to decide the ideal precipitation assortment tank volume and assess the utilization of such a framework in specific areas. It creates and collaborates with the techniques for displaying and mapping fields and water profitability of downpour took care of harvests in semiarid situations of India utilisinghyper-spectral and multispectral remote detecting information and connecting the information to a similar field zone information and atmosphere station information. This is to give data to propel water reaping innovations in the horticultural grounds of the semi-dry situations of India.
\end{abstract}

Keywords:-rainwater harvesting, soil moisture, hyper-spectral, multispectral, semi-arid environments

\section{INTRODUCTION}

Agriculture Sector is the major contributor to the economy of a nation and $70 \%$ of the population in our country depend on the Agriculture and its allied sectors.Counterfeit utilization of water to the dirt for helping with developing yields is known as Water system. For farming profitability process it is basic info and urgent in the rural, social and financial development of the country. The vast majority of the water system frameworks are worked physically. These out of date methods are supplanted with semi-computerized and robotized systems. Jettison water system, dribble water system, terraced water system and sprinkler framework are the accessible customary procedures. In light of expanded interest for higher farming efficiency, terrible showing and diminished accessibility of water for agribusiness the worldwide situation of water system is ordered. By utilizing a computerized framework for water system the above issues can be amended.

The systems require logically human intervention and are repetitive. So present day advancement is required to decide the issue and should support better Water framework The board. For this, we can have a framework which is"Internet of Things (IoT) based Automatic Irrigation System using Wireless Sensor Network (WSN)".WSN has the limit of correspondence, estimation and recognising. An augmentation between the veritable physical world and virtual universes can be given WSN. 
It has a wide extent of employments in home robotisation, normal establishment, science, security and cultivating.

Water utilizes are ordered into two kinds destructive and non-wasteful Utilization is one which there is water misfortune that is the amount that comes out is not exactly the amount that is come back to the stockpile, then again, non-immoderate is one in which there are no base misfortunes or misfortunes that can be viewed as invalid

Most maintainable construction regulations compel or suggest the establishment of Rainwater harvesting system (RHS) in structures to accomplish supportable advancement objectives. The across the board impression of RHS, as naturally neighborly activity frameworks from its advantages for coordinated water the board procedures. The achievement of water reaping frameworks relies to a great extent upon the distinguishing proof of reasonable destinations and their specialized plan. A few strategies have been created for choosing destinations and procedures appropriate for Rainwater Harvesting (RWH). Many field areas and house gardening purposes we use the rainwater harvesting method by this way we can predict the amount of water that will be used for fields and household purposes. Choosing fitting locales for various RWH innovations in bigger zones is a significant test

The water reaping from the housetop increases a ton of enthusiasm for bone-dry nations. This paper proposed a reenactment for a water gathering framework to store the precipitation, so it could be a helpful wellspring of water.

The rainwater harvesting framework will gather the overflow from the top of the structure. The framework as a rule comprises of a catchment territory, a channel, a capacity tank and funnels, The capacity tank limit is one of water collecting framework and most significant parameter. The measure of water assortment and the utilization of the water sought after must likewise be thought about.

This paper mainly used for the development of an rainwater harvesting for different agricultural fields in various situations like if the field is wet or dry,and it promotes the economical growth and it also helpful in the recycling of the rainwater.

a) The Main Problems Are Associate with the Farmers Crops need adequate water which isn't accessible at whatever point required.Farmers not ready to utilize water effectively. Ranchers need to go to the particular agribusiness ranch for watching the water level, dampness level just as soil dampness. Once in a while, the rancher is absent at the homestead; around then wild animal for the most part assaults crops, so tremendous misfortunes happen.

b) Answer for the Problem need to modernize farming, appropriate water system method by water reaping. By utilizing the idea of the Internet of things, we can maintain a strategic distance from these sorts of issue later on.

\section{II.LITERATURE SURVEY}

In spite of the fact that India gets adequate measure of precipitation and have numerous enormous stream frameworks yet at the same time just a single third of the absolute horticultural land is associated by means of channel water system framework. Remaining dominant part of the segment is reliant on storm or then again tube wells. Spots with overabundance water faces issue of land rational soundness due to over water system and water logging. Water gathered on a superficial level additionally squares pores in the dirt and murders gainful microorganisms. On the other hand, places with constrained supply of water can't do water system all through the developing season in light of the fact that the necessity of water frequently surpasses the supply because of customary kind of water system like sprinkler or in the event that permitting the water to simply flood the field legitimately from water seepage channels

[1] This project was accomplished for a decent motivation in agriculture field since this arrangement of water assortment is a truly practical alternative to take care of a water system framework, utilizing this idea satisfactory and that this will be equipped for providing the whole water system framework covering the whole nursery territory without the need to separate water from some other source.In expansion, we leave a water outlet without interfacing yet, this so as to work later on associating it to different channels that will be bound to applications like the water supply for the restrooms of the workforce. As we are not in the stormy season until further notice it will be hard to get consequences of this venture promptly, so it is fitting to make reference to that the physical outcomes that we acquire as far as our task will take about a year to show, since it is a framework intended To work during the time as indicated by the varieties that happen during this year.

[2] It creates approaches and techniques for demonstrating and mapping area and water profitability of downpour took care of harvests in semiarid situations of India utilizing hyper-ghastly, hyperspatial, and progressed multispectral remote detecting information and connecting the equivalent to handle plot information and atmosphere station information. The overall objective is to give data to propel water reaping advances in the farming croplands of the semi-dry situations of India by 
leading exploration in a delegate pilot site in Jodhpur,Rajasthan.

[3]The all out water supply from housetop precipitation collecting can be assessed from the all out regions of structures and the normal volume precipitation over every zone and a spillover coefficient of 0.8 . The vast majority of the water is gathered from region $\mathrm{B}$ as it has the biggest region of building so endeavours should concentrate on this territory. The ideal water tank volume for every territory type ought not surpass the most extreme all out volume of precipitation at that zone. Contingent upon the water reaping framework as a wellspring of water will diminish the water supply rate.

[4] This commitment portrays the elements of a water collecting framework with the end goal of a control building challenge issue. The model usage in Matlab just as the information for unsettling influence age is made accessible on the site of the South African Council of Automation and Control. The dynamic framework, however basic, represents an intriguing control challenge in view of the target to improve the general working expense and the effect of the aggravations, for example, precipitation, water accessibility and family unit utilization.

[5] To stay away from association of go between and their unfavourable impacts on ranchers we proposed an IoT based arrangement, to educate the purchasers (organisations) about the merchandise delivered by a rancher. The rancher simply need to swipe his approved RFID card and afterward consequently it will send an email to the purchaser sharing the data of amount of products delivered at that moment of time.

[6] Different frequencies of light assumes explicit jobs for plant development since various photosynthetic shades inside plants .Drip water system utilizing soil dampness sensor use various frequencies. During morning, leaves get it legitimately from sun yet so as to help up the pace of development, we have furnished the nursery with plant developing lights which will divert on at whatever point the perusing from LDR sensor falls underneath cut-off worth.

\section{BLOCK DIAGRAM /FLOW CHART}

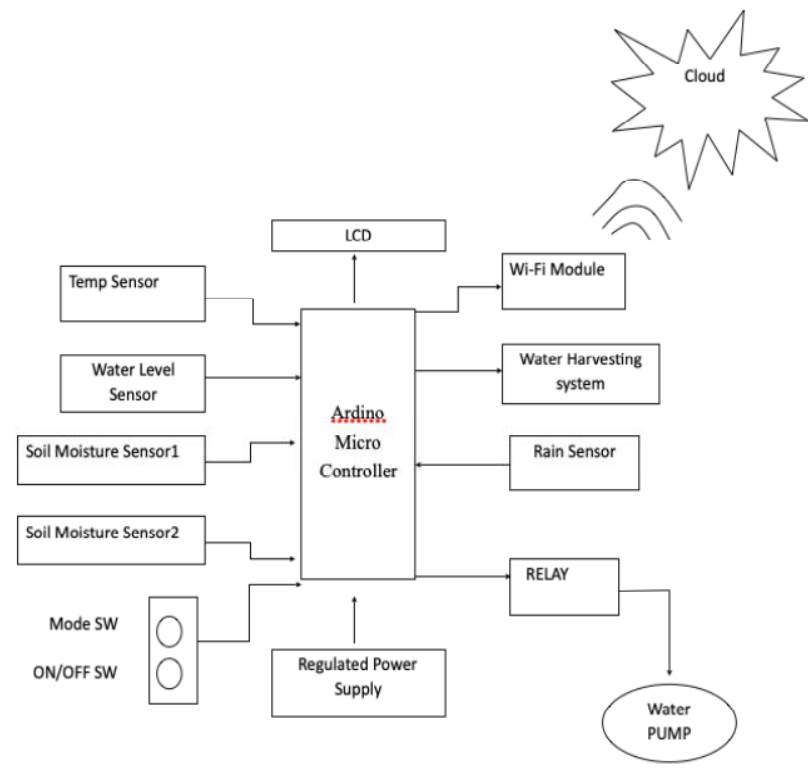

Fig 1

\section{MATHEMATICAL REPRESENTATION}

Decision making based on the data collected from IOT based sensors used in the agriculture land.

$$
\begin{aligned}
& y \rightarrow f(x) \\
& X(i j) \in i=0,1,2,3 \ldots \ldots i=i \text { th sensor }
\end{aligned}
$$

$j=$ attribute in the data sent by the ' $i$ 'th sensor

$\mathrm{j} \rightarrow 0$ to $|\mathrm{m}|$ where $\mathrm{m}$ is no of data columns

if $\mathrm{f}(\mathrm{x})$ evaluates the value

Return message

else

Automate the levels

* as above we can see the mathematical form of the working of this model.let $\mathrm{y}$ be the out put from doing an action $\mathrm{f}(\mathrm{x})$, where $\mathrm{X}$ is influenced by the two parameters $(i, j)$ and $I$ is the ith sensor and $j$ is the data sent by the ith sensor.

* If the output $\mathrm{f}(\mathrm{x})$ returns the estimated value i.e, 1 then do the action.

* Else the module requires the manual control.

\section{RELATED WORK}

As soon as connects power supply to the system Aurdino micro controller ,LCD,ADC,TIMER, UART will get initialise and system will be in sensor mode by default. AsShown in fig.1

1. System is Having Two Modes

A. Auto mode (Sensor Mode)

B. Manual Mode 
A. Auto Mode:

In this Mode Irrigation is controlled and depends on the moisture and temperature sensor threshold levels. Sensor Threshold Levels for each crop is already set in the algorithm written in the controller. Farmer needs to select the crop button as per the cultivation. The status of the sensor will be sent to the Thing-speak cloud.

A. Manual Mode.

To select this mode Farmer needs to press mode button once to change the system from Auto Mode to Manual Mode. Once Manual Mode is selected then system won't work on sensor threshold levels. One needs to press manual ON/OFF switch to pump ON and OFF.

2. Water Level Sensor is Used to monitor the water level in the well/Tank .If water is preset then only controller will allow pump to turn $\mathrm{ON}$.

3. LCD will Display the status of the sensor and pump.How much Water is present is displayed on LCD in Lts.

\section{COMPONENTS IDENTIFIED}

1. Arduino microcontroller

2. $16 \times 2$ LCD

3. Temperature Sensor

4. ESP8266

5. Moisture Sensor

6. Water Level Sensor

7. Adaptor

8. Relay

9. Water Pump

\section{VII.APPLICATIONS}

\section{Agriculture:}

Concerning Urban cultivating water procuring in urban areas diminishes the impact of flood and flooding. The blend of urban 'green' roofs with water catchments have been found to reduce building temperatures by more than 1.3 degrees Celsius. Water procuring identified with urban agriculture would be an appropriate strategy to help meet the Unified Countries Manageable Improvement Objectives for cleaner and sensible urban zones, prosperity and flourishing, and sustenance and water security. The development is open, regardless, ought to be revamped in order to use water even more viably, especially in a urban setting.

\section{Domestic use:}

In China, Argentina, and Brazil, roof water gathering is used to give drinking water, private water, water for tamed creatures, water for little water framework, and a way to deal with energize groundwater levels. Gansu zone in China and semiarid upper east Brazil have the greatest roof water gathering adventures going on.

About $40 \%$ of Thailand's common people utilizes water collecting. Water gathering was progressed enthusiastically by the organization during the 1950s. During the 1990s, after government financing for the arrangement tanks ran out, the private division stepped in and gave a couple million tanks to private nuclear families, tremendous quantities of which continue being used today.This is maybe the greatest instance of selfsupply of water far and wide.

\section{Industry}

Frankfurt Air terminal has the best water gathering structure in Germany. The structure helps save around 1 million cubic meters of water each year. The cost of the system was 1.5 million dm (US\$63,000) in 1993. This system assembles water from highest points of the new terminal which has a locale of 26,800 square meters. The water is assembled in the basement of the air terminal in six tanks with a limit cutoff of 100 cubic meters. The water is essentially used for can flushing, watering plants and cleaning the cooling structure.

\section{CONCLUSION AND FUTURE WORK}

The paper gives an Earth Observing (EO) information put together methodology with respect to creating techniques to supply data that bolsters progression in water gathering advances of the horticultural croplands inside the semi-bone-dry conditions. The final word objective of the examination is to help advance harvest profitability (efficiency per unit of land) and water (profitability per unit of water) inside the downpour took care of territories of semi-bone-dry conditions bringing about expanded nourishment creation and nourishment security.

With more advancement within the field of IoT expected within the coming years, these systems are often more efficient, much faster and fewer costlier. within the Future, this technique are often made as an intelligent system, where within the system predicts user actions, rainfall pattern, time to reap, animal intruder within the field and communicating the knowledge through advanced technology like IoT are often implemented in order that agricultural system are often made independent of human operation and successively quality and large quantity yield are often obtained. 
[1]."Rainwater harvesting for household use"-M.F. Colom Reyes, A. Soriano-Gómez, J.M.Hernández- Martínez Civil Engineering School Universidad Autónoma de Querétaro Querétaro, México -IEEE2019

[2]. Earth Observing Data and Methods for Advancing Water Harvesting Technologies in the Semi-arid Rain-fed Environments of India Chilka Sharma Research scholar, MDS University, Ajmer - India

[3]. Rooftop Rainwater Harvesting System in Amman City Ola M. Surakhi University of Jordan Amman, Jordan ola.surakhi@gmail.com.

[4]. A residential rainwater harvesting system as a control engineering challenge problem* Lidia Aureate and Margret Bauer, Member, IEEE
[5]. D. S. Kim, T. H. Shin, and J. S. Park, "A security framework in rfid multi-domain system," in Availability, Reliability and Security, 2007. ARES 2007. The Second International Conference on, April 2007, pp. 1227-1234.

[6]. M. Mahdavian, M. B. Poudeh, and N. Wattanapongsakorn, "Greenhouse lighting optimization for tomato cultivation considering realtime pricing (rtp) of electricity in the smart grid," in Electrical Engineering/Electronics, Computer, Telecommunications and Information Technology (ECTICON), 2013 10th International Conference on, May 2013, pp. 1-6. 